\title{
Beliefs and practices in the assessment of workplace pollutants
}

\author{
Submitted: 15 December 2004 \\ Accepted: 29 August 2005
}

\section{Summary}

Objectives: A survey was undertaken among Swiss occupational hygienists and other professionals to identify the different exposure assessment methods used, the contextual parameters observed and the uses, difficulties and possible developments of exposure models for field application.

Methods: A questionnaire was mailed to 121 occupational hygienists, all members of the Swiss Occupational Hygiene Society. A shorter questionnaire was also sent to registered occupational physicians and selected safety specialists. Descriptive statistics and multivariate analyses were performed.

Results: The response rate for occupational hygienists was $60 \%$. The so-called expert judgement appeared to be the most widely used method, but its efficiency and reliability were both judged with very low scores. Long-term sampling was perceived as the most efficient and reliable method. Various determinants of exposure, such as emission rate and work activity, were often considered important, even though they were not included in the exposure assessment processes. Near field local phenomena determinants were also judged important for operator exposure estimation.

Conclusion: Exposure models should be improved to integrate factors which are more easily accessible to practitioners. Descriptors of emission and local phenomena should also be included.

Keywords: Occupational hygiene - Exposure assessment Exposure determinants - Exposure models - Expert judgement.

Estimating exposure is an important step in occupational health studies, both retrospective, and prospective. Preventive measures and corrective actions against pollutants exposure at the workplace are frequently based on this estimate. It may also play a key role in the recognition of occupational disease. Exposure estimates to chronic pollutants is the traditional field of occupation hygienists and, to a lesser extent, of occupational physicians and occupational safety specialists (e.g. safety engineers).

For chemical exposure, direct measurement is certainly the most reliable and objective way to obtain a reliable assessment of the exposure. It must however be stressed that this approach suffers major drawbacks regarding cost and technical complexity. Furthermore, direct measurements only give information on the current exposure (the day of investigation) and do not allow for past exposure estimation, or exposures under other or future conditions (Nicas 2003).

Because of these difficulties, the assessment of occupational exposure relies more and more frequently on different approaches of varying complexity. Table 1 gives a short overview of potential methods considered up to now in occupational hygiene. The most simple and most widely used approach is probably the so-called "expert judgment". Occupational hygienists evaluate whether a potential hazard exists by observing workplace conditions and interviewing the exposed workers about the materials used, the production levels, the duration of exposure, existing preventive measures and so on. Exposure assessment is thus based on an interpretation of observations and interviews, integrated with knowledge gathered from previous similar situations, either coming from the specialist's own experience or from literature reports. Despite its widespread use, there is limited information on the 'expert judgement' processes. These subjective estimates are usually unstructured opinions, difficult to explain objectively and to transfer to others (Jayjock 1997).

In the absence of current monitoring data, semi-quantitative methods have been developed to estimate historical or 
future exposures. For example, a Job Exposure Matrix could provide a practical and less time-consuming method, using historical data through a cross classification of job titles by substances (Dosemeci et al. 1990). This approach, however, is limited in its details and cannot give information on specific exposure situations. Cherry \& Schneider (1999) have developed and validated a structured approach to assess exposure based on descriptive information about work activity and work environment. In this study there was a reasonable association between the estimated exposure level and the measurements, with the correlation between the log-transformed measurements and estimates mostly between 0.5 and 0.9 .

A more detailed model was developed in England to better describe workplaces with available historical data (Cherry et al. 2003). Estimation and Assessment of Substance Exposure (EASE) is a semi-quantitative empirical model that gives ranges of potential exposures based on an analysis of exposure measurements contained in the UK National Exposure Database (NEDB). In fact, a selection of exposure determinants is included in the model, and their influence is estimated based on past exposure measurements. This allows the user to make predictions using a simple description of workplaces and processes.

On the other hand, indoor air quality modelling represents a more systematic, transparent and consistent method to integrate numerous parameters. Available deterministic models, based on physico-chemical principles, such as ventilation characteristics, pollutant generation rate, and mass transport mechanisms, provide a convenient way to structure all significant factors determining the levels of exposure.

The Ideal Mixed Model relies very simply on the concept of mass conservation and of homogeneous concentration throughout a single workplace volume. This model is one of the older and more known models in occupational hygiene, and its best advantage is its simplicity (Keil 2000). A more complicated workplace description is found in the Two Zone Model (Nicas 1996; Nicas 2003; Cherry 1999), which divides the room into two conceptual zones, one near the source (near field) and the other represented by the rest of the room (far field). The Eddy Diffusion Model has notable advantages over the previously described models as it can take into account the gradual decrease of concentrations when moving away from the source (Roach 1981; Wadden et al. 1989). The Gaussian Plume Dispersion model (Mulhausen 1998) is based on a diffusion model that takes into account the direction of air currents. Tools developed by the Environmental Protection Agency (Daniels et al. 2003), such as ChemSTEER, MultiChamber Concentration and Exposure Model or Wall Paint Assessment Exposure model, are based on several of the above models, and represent therefore combinations of them. Finally Computational Fluid Dynamic (CFD) (Bennet et al. 2003) is a powerful tool that makes it possible to estimate the pollutant's concentration everywhere in a workplace, once the appropriate boundary conditions (like pollutant generation and air flow throughout the room) are specified.

These models can be used to provide specific ventilation requirements under different assumption for production rate, chemical consumption or air mixing conditions (Olcerst 1999). Models have also been developed for a quantitative reconstruction of historical exposures (Rong et al.1990; Cherry et al. 1999; Kauppinen 1994).

The work presented here is part of a larger research project aimed at improving workplace exposure estimations through modelling techniques. The objective is to improve the conditions under which the "expert judgments" take place, by developing (through a revision of the existing models) an assessment tool in accordance with the experts' needs, based on parameters, which are simple and more easily accessible. To identify current job practices as well as the parameters, which are more easily accessible during field investigations, a questionnaire has been proposed to the members of the Swiss

\begin{tabular}{|c|c|c|}
\hline Type of method & Main characteristics & Main requirements \\
\hline Direct measurement & objective & laboratory facility \\
\hline Expert judgement & subjective & professional experience \\
\hline JEM & historical & historical data \\
\hline EASE & empirical & empirical model structure \\
\hline One-Zone Model & $\begin{array}{l}\text { physical, well-mixed, } \\
\text { compartmental }\end{array}$ & emission, air-change \\
\hline Two-Zone Model & $\begin{array}{l}\text { physical, compartmental, } \\
\text { near-field exposure }\end{array}$ & $\begin{array}{l}\text { emission, air-change, } \\
\text { inter-compartment flow }\end{array}$ \\
\hline Eddy-Diffusion Model & physical, diffusivity & emission, diffusion coefficient \\
\hline Gaussian Plume Model & physical, directivity & emission, directivity, air velocity \\
\hline CFD & $\begin{array}{l}\text { physical, fluid dynamic and } \\
\text { heat transfer }\end{array}$ & $\begin{array}{l}\text { emission, turbulence, momentum } \\
\text { effects, buoyancy }\end{array}$ \\
\hline
\end{tabular}

Table 1 Main approaches to exposure assessment, its characteristics and main requirements 
Figure 1 Distribution of the occupational hygienists in the different economic sectors

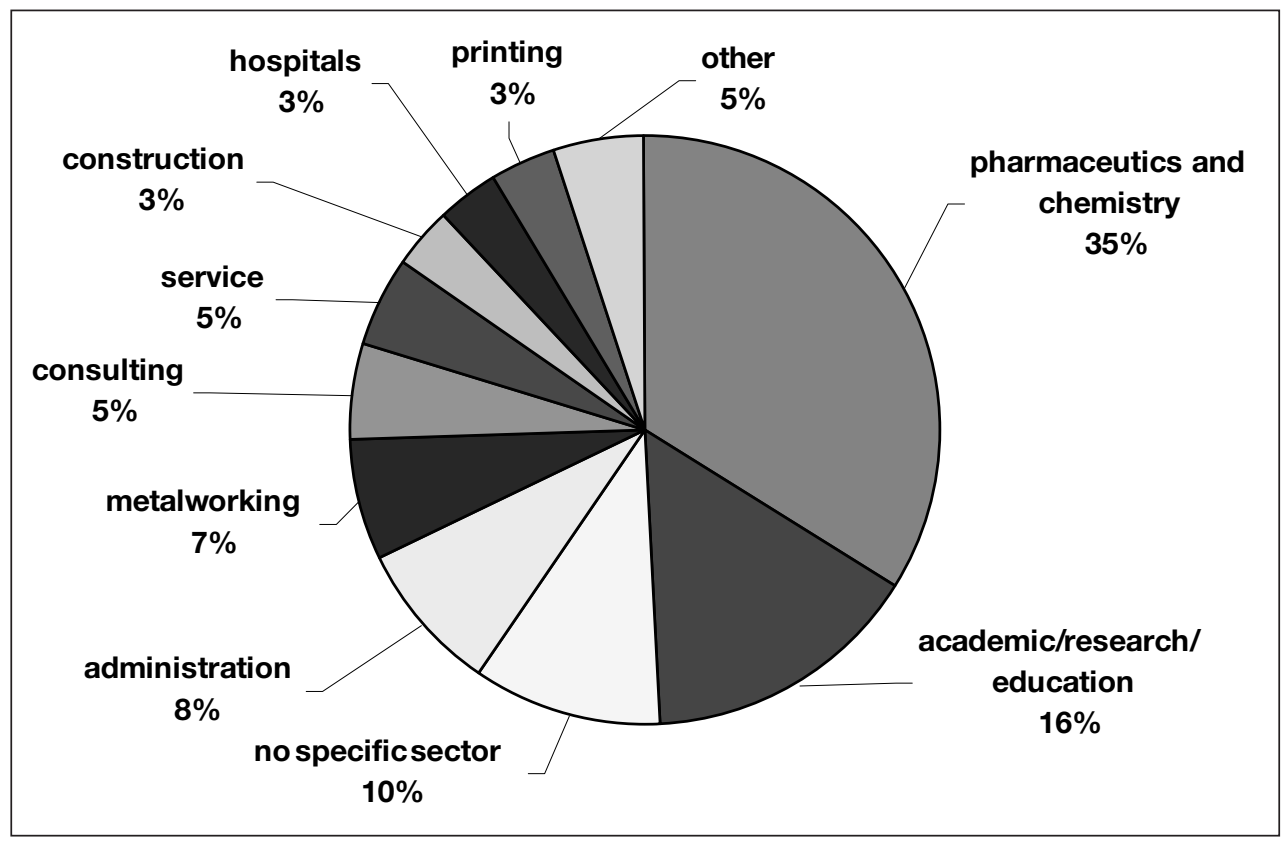

Occupational Hygiene Society. The questionnaire explores the methods used in Switzerland to assess chronic and sub-acute exposure to pollutants at workplaces, and identifies the key factors involved in the emission and dispersion phenomena, which are used by practitioners during an exposure assessment.

\section{Methods}

In a first phase, a questionnaire was sent to the 121 members of the Swiss Society of Occupational Hygienist. The questionnaire was structured into five different sections specifically aiming to:

- appreciate the practitioners' background and basic activities in the field of occupational hygiene and/or exposure assessments;

- identify the assessment methods, which are used and perceived as more efficient and more reliable to assess chronic and sub-acute exposure chemical pollutants (such as gas, vapour or dust) at the workplace;

- compare the relative importance of the parameters (and their utilisation frequency) observed by the specialists to assess the exposure situation (chronic and sub-acute exposures) during expert judgement (without any objective measurements or empirical or theoretical exposure models);

- identify the physico-chemical parameters considered as most relevant by practitioners during quantitative exposure assessment;

- assess the use of emission and dispersion models in terms of frequency and perceived accuracy and efficiency, and analyse the needs and the difficulty of the practitioners in using exposure models.

Most questions were multiple-choice questions, with predefined frequency classes or ranks ranging from 1 (lowest) to 6 (highest).

In a second phase, a similar questionnaire, but reduced to sections 1 to 3, was sent to a selected group of 95 members of the Swiss Society of Occupational Safety involved in exposure assessment and to 169 occupational physicians, members of the Swiss Society of Occupational Medicine.

Global results were analysed by descriptive statistics. In some cases they were analysed by groups in order to identify differences. Then the Chi square test was performed to find possible dependencies between two variables, followed by a factor analysis of correspondences if necessary. The $\mathrm{p}$-values reported in the text are those obtained from the Chi Square test of dependency.

We report here results obtained after the analysis of occupational hygienists questionnaires. Selected information obtained from the other occupational health specialists is also presented when needed.

\section{Results and discussion}

Seventy-seven questionnaires were returned by occupational hygienists. Five of them, which were returned by hygienists not involved in exposure assessment, were blank ones. Positive response rate was therefore $59.5 \%$. It should, however, be noted that not all the returned questionnaires were filled completely (only $50 \%$ ). 


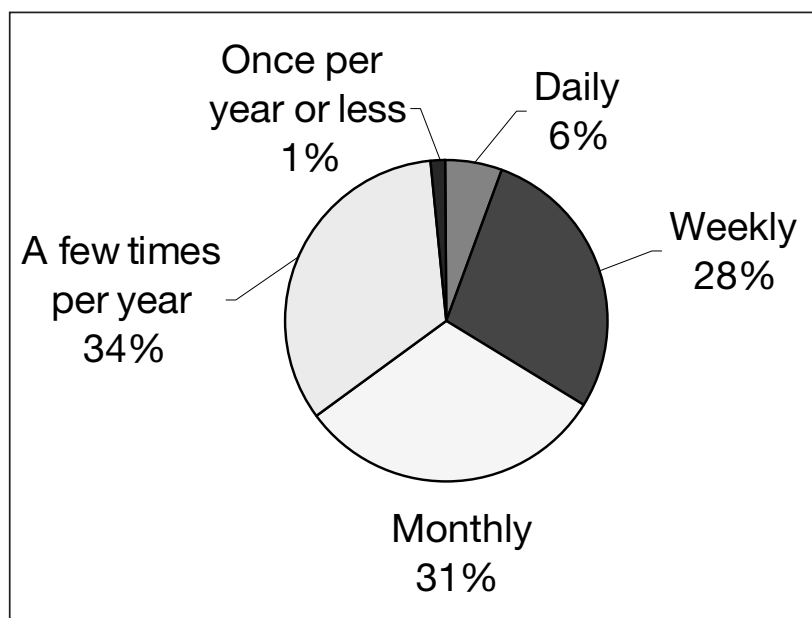

Figure 2 Distribution of the frequency of activity of occupational exposure assessment

\section{Background Information}

Surveyed occupational hygienists were equally distributed into the following job categories: advisory or consulting body, industry/service and authority. Fifteen percent could not identify themselves in these categories (most of them in academic research) and some fell into more than one category.

Distribution of the occupational hygienists in various economic sectors is shown in Figure 1. Most occupational hygienists $(35 \%)$ are employed in the pharmaceutical and chemical industry. Data about initial training also indicates a similar trend: $59 \%$ of the occupational hygienists have had a first training in chemistry, $11 \%$ in environmental science, $10 \%$ in biology, $8 \%$ in medicine, and $12 \%$ in other fields.

Fifty percent of the occupational hygienists followed the single postgraduate course existing in Switzerland, $9 \%$ followed other international specialized training/courses, and the others specialized through on-the-job training. Seventy-three of the respondents were certified by the Swiss Occupational Hygiene Society.

Most surveyed occupational hygienists have a relatively short experience in the profession, with $50 \%$ having less than 10 years. This needs to be seen in relation to the fact that in
Switzerland, a pertaining legislation was introduced only recently, requiring companies to call on occupational hygienists (introduced in 1996, implementation deadline in 2000). A dependency was found between the experience and the way the hygienists acquire specialisation. Hygienists with less than 8 years of experience are specialized through a postgraduate course $(\mathrm{p}$ value $=0.02$ ), whereas those with more than 8 years are specialized through practice ( $\mathrm{p}$ value $<0.01$ ).

Occupational hygiene activities is the main occupation of only $60 \%$ of the hygienists. This changes according to the economic sector: for industry/services or authority categories almost $80 \%$ of the hygienists identify occupational hygiene as their main activity. The frequencies reported for exposure assessment activities are shown in Figure 2. 34\% of hygienists perform exposure assessment weekly or daily. This frequency is linked to the time spent in occupational hygiene activities, $60 \%$ of the hygienists whose main activity is occupational hygiene report they perform workplace exposure assessments weekly or daily. Finally, 50\% of the occupational hygienists report assessing exposures in all kinds of environments. As shown in Figure 3, industrial environments are the main focus of exposure assessment activities.

\section{Methods for Assessing Workplace Exposure}

Figure 4 presents the frequencies of use for the different exposure assessment techniques. Exposure models and biological monitoring are seldom used: $60 \%$ of occupational hygienists have never used models, while $52 \%$ have never made use of biological monitoring. The results obtained for those making use of models are hardly more encouraging. $30 \%$ of hygienists report using model and biological monitoring rarely (in less than $10 \%$ of exposure assessment).

These results were somehow expected for biological monitoring, which falls traditionally in the field of occupational physicians. However, the results obtained for exposure models are surprising. It appears that a significant number of occupational hygienists are unfamiliar with the existing modelling tools and with the modelling capabilities. $30 \%$ of them were indeed unable to give a ranking of the models' efficiency and reliability.
Figure 3 Different workplace environment assessed by hygienists

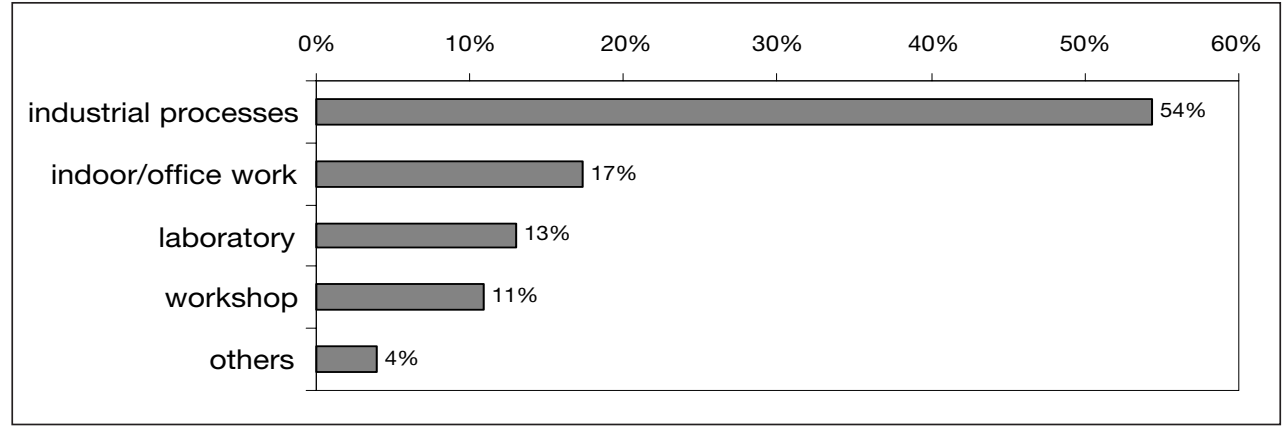


Figure 4 Frequency of use of the different exposure assessment techniques

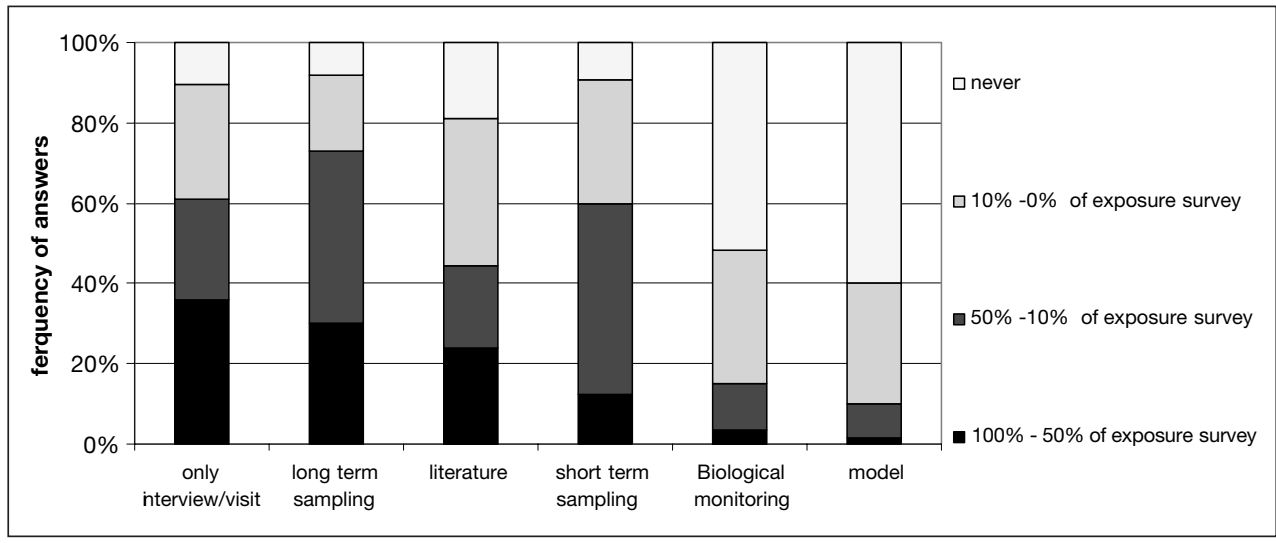

The most frequently used exposure assessment techniques are the interview/visit (expert judgement) and the long term sampling. Although the interview/visit method obtained the higher score in frequency of use, it obtained almost the lowest score in efficiency and reliability (only exposure models get a lower score).

Experience plays a significant role in field practice. On the one hand, hygienists having an initial formation in chemistry tend to score expert judgement as less efficient ( $\mathrm{p}$ value $=$ 0.01 ). On the other hand, hygienists with more than 8 years of experience frequently use expert judgment ( $\mathrm{p}$ value $<0.01$ ) and tend to score it as more efficient ( $\mathrm{p}$ value $<0.01$ ). It is interesting to note that hygienists with less than 8 years of experience make use of literature more often $(p$-value $=0.04)$ and believe it to be more efficient than expert judgment alone ( $\mathrm{p}$ value $=0.02)$.

For most of the surveyed hygienists, long-term sampling obtained the best scores, both with regard to efficiency and to reliability. Unsurprisingly, occupational hygienists used exposure measurements $(\mathrm{p}$ value $=0.01$ ) whereas occupational physicians employed biological monitoring more often $(p$-value $=0.01)$ and at the same time found it more efficient $(\mathrm{p}$ value $=0.02)$.

After sorting by economic sector, experience or initial training, the results did not show any evident trend. In the case of safety specialists, exposure judgement is even more in use compared to other methods, while literature information is not considered at all.

\section{Use of the expert judgement}

We have seen previously that occupational exposure assessment relies most frequently on employee interview and/or workplace visit, a so-called "expert judgment". This procedure is often seen as a "black-box" process, a mental process, which is not easily transferable to others (Jayjock 1997; Schneider 2002). This is also reflected by the fact that, despite its frequent use, specialists have little confidence in it.
To clarify this process, occupational hygienists were asked about the frequency of use of several exposure determinants and their perceived influence on exposure. Eighteen different factors were considered in the questionnaire. They could be divided into 4 classes:

- workplace: room size and shape, natural ventilation, forced ventilation, air currents and direction of air currents within the room;

- emission: rough mass balance, evaporation area, vapour pressure or boiling point for volatiles, composition and dilution, presence of air jet at the source, type of emission process (e.g. grinding, spraying);

- worker's activity: method and degree of manual handling, frequency of activity intensity, use of personal protective equipment;

- general: general cleanness, sensations such as odours or irritation, movement of people/objects in the room and air temperature gradient in the room.

The results for the 4 groups of parameters are presented in Figure 5. It is shown that occupational hygienists frequently use parameters associated with the worker's activity and also believe them to have an important influence on exposure. These parameters are furthermore easily observable. Parameters of the workplace itself are also very often used by most occupational hygienists, although they are considered to have less influence on exposure. It is interesting to note that these parameters may control exposure only indirectly, by a dilution in the far field, but that they can be easily evaluated.

On the other hand, the elements associated directly with the emission process are not so often observed during an "expert judgement" even though they were considered quite important. (These parameters are difficult to quantify, but they play a key role in exposure).

Finally, some parameters describing the general conditions in the workplace, such as air temperature, temperature gradient, movement of people, are perceived as not important and are rarely used. 
Figure 5 Influence on exposure (\% of hygienists answers between score 5 and 6 ) versus utilisation rate $(\%$ of hygienists answers with an utilisation rate between 50 and $100 \%$ ) for the different groups of parameters

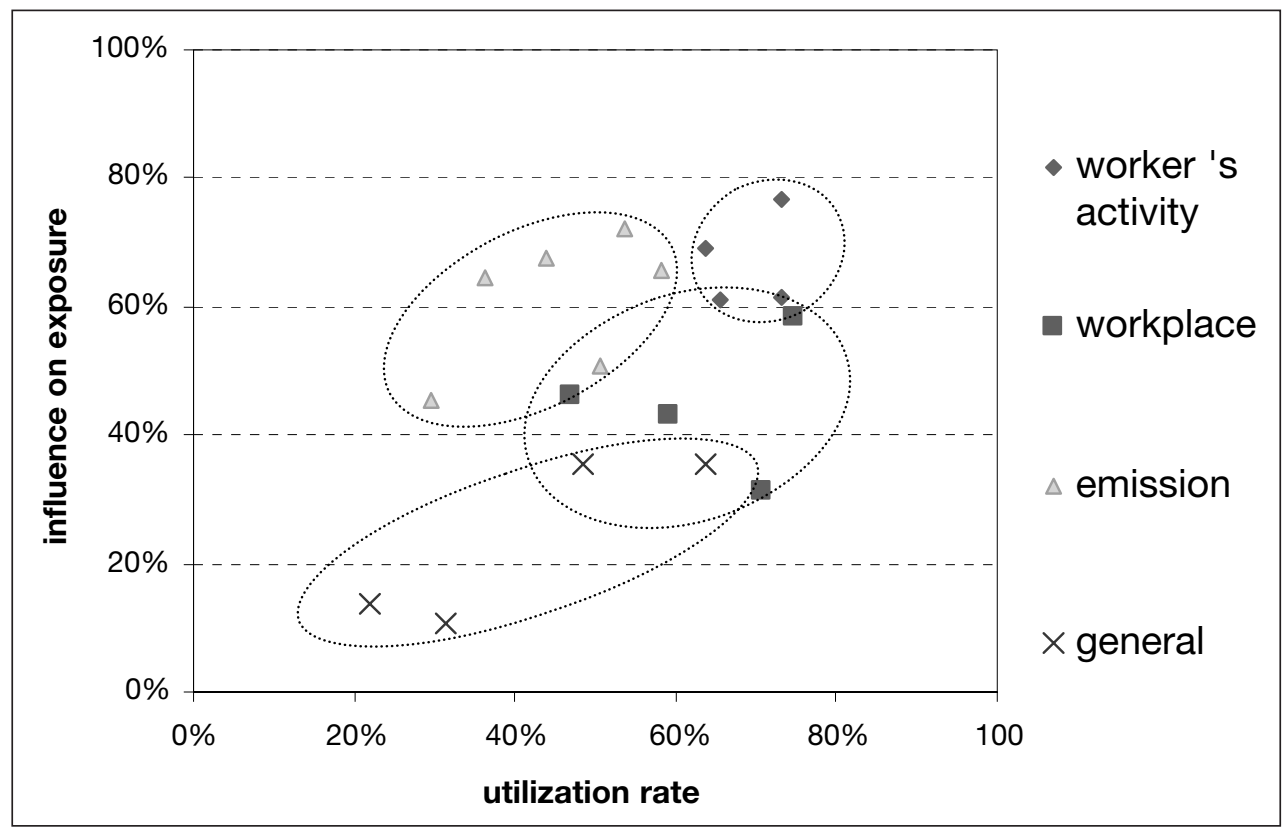

\section{Relevant exposure parameters}

This section of the questionnaire was designed to describe how important occupational hygienists consider the various physico-chemical parameters that control emission and dispersion of pollutants.

For solvents, most occupational hygienists selected the higher scores (between 5 and 6) for all factors proposed (vapour pressure, surface of evaporation, air temperature, ventilation near the source, agitation), except for molecular diffusivity. In the case of aerosols, the parameter which was judged of primary importance was particle size and distribution. In fact, aerodynamic behaviour of aerosols (such as settling over time, penetration and deposition in the lungs) is strongly dependent on particle size. Still, parameters such as the air velocity and direction at the source, as well as the separation forces associated with the process (grinding, air jet pressure ...) also obtained high scores. It is clear that the emission of aerosols is closely related to the energy given to the generation process, such as separation forces (as fracture, abrasion, agitation, for dry aerosols, or atomisation and spraying for the liquid droplet); but it could also depend on the property of the specific material, such as the cohesion forces (the degree of dustiness in the case of a solid, the surface tension forces in the case of a liquid) (Vincent 1995; Reist 1993)

Local ventilation was considered the most effective control measure, controlling worker exposure at the source and preventing migration into the room environment. General ventilation was also judged important, as it ensures dilution of pollutants by providing properly conditioned air.

\section{Use of exposure models}

The use of predictive models, either of semi-quantitative (Job Exposure Matrix, EASE) or physical nature (compartmental, diffusion model) is clearly underdeveloped. $60 \%$ of the occupational hygienists never make use of models to assess occupational exposure situations, relying exclusively on qualitative expert judgment or measurements. The reasons given for not using models were mostly their limitations. $40 \%$ of them reported difficulties in representing real-life work situation in terms of model parameters. $22 \%$ of them invoked the lack of accuracy/precision and the time-consuming process required. Still, it must be stressed that $16 \%$ of the hygienists reported they didn't use the predictive model because they didn't know it.

Understanding the use of predictive models amongst practitioners was a prime concern in this study. A full section of the questionnaire was therefore dedicated to this specific topic. Unfortunately, only $28.5 \%$ of the hygienists filled this section. This may easily be explained by the fact that models appear to be used to a limited extent. Moreover, most of the questions implied a relative ranking thus requiring simultaneous knowledge of several of them. The number of answers obtained is too scarce to conduct a statistical analysis or get conclusive results, although some tendencies can be observed.

One concern in the use of models is the difficulty to assess the emission rate correctly. It is interesting to note that hygienists using models favour practical approaches to estimate emissions (i.e. through mass-balance or measurement). As shown in Figure 6, emission rates are usually estimated either through mass-balance, measurement in exhaust air or by us- 
Figure 6 Distribution of utilisation rate of the different methods to identify the generation rate when the exposure is assessed through a model $(n=25) s$

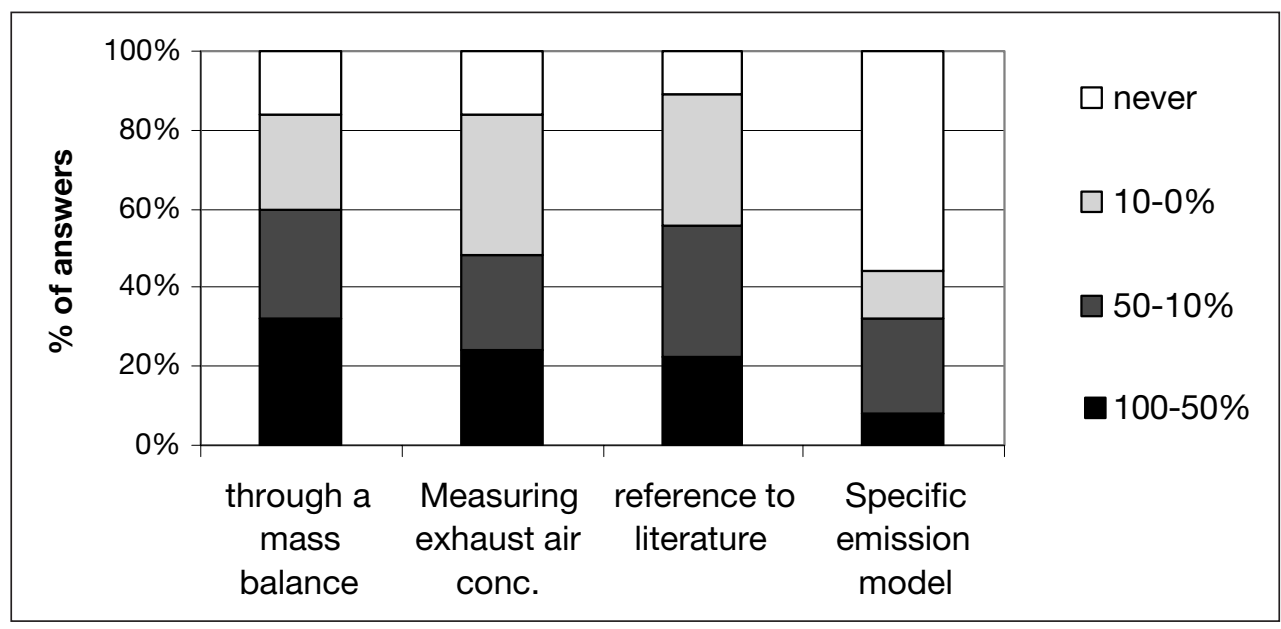

ing data reported in the literature. The use of specific models is less common, which suggests a limited confidence in the existing predictive emission tools.

It is assumed that two factors play a key role in the selection of a modelling tool: its accuracy, which should fit with the level of precision required in the assessment, and its effectiveness, namely its capacity to produce usable results at the lowest investment costs (time, resources ...). On the one hand, banding approaches (job exposure matrix), compartmental models (ideally mixed, two-zone model), and other physical models supported by user-friendly tools (EPA's tools) are considered as the most efficient because of their straightforwardness. On the other hand, physical models with a certain degree of complexity (two-zone model, EPA's tools, Gaussian model) are considered as the most accurate. Trivial physical models (e. g. ideally mixed) or models working as "black-box" for the user (e.g. EASE) are judged of poor accuracy. This tendency to give more confidence to models based on explicit and comprehensive hypotheses is not verified in the case of computational fluid dynamics. Although it is much more detailed and comprehensive than other methods, CFD is judged of mean accuracy. This result reflects perhaps the lack of confidence practitioners show in using such a complex tool correctly rather than their lack of confidence in the model itself. The number of practitioners familiar with CFD is unfortunately too limited to draw any conclusion.

Finally, $33 \%$ of the hygienists estimated that no further development of models was required, as monitoring was a better alternative anyway, while $67 \%$ believe that new developments are required in order to overcome the limitations of the existing exposure models. The two enhancements, which are referred to more frequently are: a better fitting between field and models parameters ( $70 \%$ of them) and, a better representation of dispersion phenomena near the emission source (50\% of them).

\section{Conclusion}

The present survey among Swiss occupational hygienist and other professionals showed that the "expert judgement" is the most widely used method to assess airborne exposure in Switzerland. Looking at exposure determinants, occupational hygienists observe the parameters related to worker's activity more frequently, as they believe that these factors play a key role in exposure. The parameters associated with the emission and the pollutant behaviour near the source are also judged very important, but seldom used because of their limited availability during field investigations.

A quantitative characterization of chemical emission sources is not a common practice in the field of occupational health and, consequently, is underdeveloped (Jayjock 2005). Description of the pollutant behaviour near the emission source is of particular interest as it is also stated as a prime cause of inaccuracy in the current physical models available. Most models, particularly compartmental models, do indeed take local conditions into account to a very limited extent. Local ventilation conditions or the worker's position are usually either oversimplified or not considered.

Both emission and dispersion models are used only rarely. This is probably linked to the perceived low efficiency and reliability of the existing models. To use deterministic models, even the simpler ones, certain basic parameters must be estimated such as generation rates or ventilation conditions, and in certain cases these estimations could be a serious obstacle. In addition, occupational hygienists also felt that model predictions are not so accurate and precise. It's clear that the precision of a model depends on how much it can adapt to different specific situations, but it's also important to consider how close to the "truth" the model output needs to be to allow for a decision.

However, about $70 \%$ of the occupational hygienists using 
models agreed on the necessity to develop models further They think that the most beneficial improvements of exposure models would be to include input parameters, which are more accessible during field investigations. Near source phenomena should also be taken into account more.

Despite this low overall usage of exposure models by practitioners in Switzerland, there is an interest in research institutions to apply and develop new techniques (Bruzzi 2005; Sottas 2005; Vernez 2005) in agreement with the current European and American trends (ISSA 2004). As a result of this questionnaire, future models should be more concentrated on near field conditions and at the same time they should integrate parameters which are more easily available during practical surveys.

\section{Acknowledgments}

The authors acknowledge all Swiss hygienists and Occupational Health professionals having provided detailed information on their background and practice.

The survey was undertaken in the context of a PhD Study supported by the Swiss National Science Foundation (Grant 3200B0-100343).

\section{Zusammenfassung}

Ansichten und Praktiken bei der Schadstoff-Beurteilung auf Arbeitsplätzen

Fragestellung: Eine Umfrage unter schweizerischen Arbeitshygienikern und anderen Spezialisten sollte die verschiedenen Methoden zur Expositionsbestimmung und die dabei verwendeten Bezugsparameter, sowie die Modellanwendungen, dabei auftretende Probleme und Entwicklungsmöglichkeiten identifizieren.

Methoden: Ein Fragebogen wurde erstellt und an alle 121 Arbeitshygienekern der Schweizerischen Gesellschaft für Arbeitshygiene verschickt. Eine verkürzte Fassung wurde an registrierte Arbeitsmediziner und eine Auswahl von Sicherheitsspezialisten versandt. Die Resultate wurden mit deskriptiven und multivariaten statistischen Methoden ausgewertet.

\section{Résumé}

Croyances et pratiques dans l'évaluation des polluants sur le lieu de travail.

Objectifs: Identifier les méthodes d'évaluation d'exposition les plus utilisées par les hygiénistes du travail en Suisse, les paramètres observés pendant les évaluations et leur niveau d'utilisation, ainsi que les limites et les développements possibles des modèles d'exposition.

Méthodes: Un questionnaire a été envoyé à 121 hygiénistes du travail, membres de la Société Suisse d'Hygiène du Travail. Un questionnaire restreint a été également envoyé à un groupe de médecins du travail et autres spécialistes de la sécurité au travail. Des statistiques descriptives ainsi que des analyses multivariées ont été effectuées.
Ergebnisse: Die Antwortrate der Arbeitshygieniker betrug $60 \%$. Das sogenannte Expertenurteil war die am häufigsten angewandte Methode, obschon dessen Effizienz und Zuverlässigkeit von den Arbeitshygienekern mit sehr tiefen Noten beurteilt wurde. Langzeitmessungen wurden als die effizienteste und zuverlässigste Methode betrachtet. Verschiedene Faktoren der Exposition wie Emissionsrate und Arbeitsaktivität wurden dagegen von vielen Fachleute in ihre Betrachtung einbezogen, auch wenn sie nicht direkt im Expositionsbestimmungsverfahren integriert sind. Lokale Nahfeldphänomene wurden ebenfalls als wichtig beurteilt für Operatorexpositionsbestimmungsverfahren.

Schlussfolgerung: Expositionsmodelle sollten durch den Einbezug von Faktoren, die den Fachleuten einfacher zugänglich sind, verbessert werden. Die lokalen Rahmenbedingungen (Nahfeldphänomene) und die Emissions-Parameter sollten in die Modelle integriert werden.

Résultats: Le taux de réponse pour les hygiénistes du travail était de $60 \%$. Le jugement d'expert est la méthode la plus utilisée, mais son efficacité et sa précision ont été jugées médiocres. Des prélèvements réguliers sur une longue période sont perçus comme la méthode la plus efficace et la plus fiable. Certains déterminants d'exposition comme le taux d'émission et l'activité du travailleur sont souvent considérés comme importants, mais ils ne sont pas inclus dans les modèles actuels. L'environnement semble important pour l'évaluation de l'exposition.

Conclusion: Les modèles d'exposition existants devraient être améliorés pour intégrer des facteurs plus facilement accessibles aux praticiens. Les conditions locales ainsi que les paramètres d'émission devraient aussi être inclus dans ces modèles. 


\section{References}

Bennett JS, Feigley CE, Khan JA, et al. (2003). Comparison of emission models with computational fluid dynamics and a proposed improved model. Am Ind Hyg Assoc J 64: 739-54.

Bruzzi R, Vernez D, Sottas PE \& Droz PO (2005). Exposure models in Switzerland. An overview of the present situation. Gefahrstoffe Reinhaltung der Luft (in press).

Cherrie JW (1999). The effect of room size and general ventilation on the relationship between near and far field concentrations. Appl Occup Environ Hyg 14(8): 539-46.

Cherrie JW, Schneider T (1999). Validation of a new method for structured subjective assessment of past concentrations. Ann Occup Hyg 43 (4): $235-45$.

Cherrie JW, Tickner J, Friar J, et al. (2003). Evaluation and further development of the EASE model 2.0. Norwich: Her Majesty's Stationery Office.

Daniels W, Lee S, Miller A (2003). EPA's exposure assessment tools and models, Appl Occup Environ Hyg 18(2): 82-6.

Dosemeci M, Stewart PA, Blair A (1990). Tree proposal for retrospective, semiquantitative exposure assessments and their comparison with other assessment methods. Appl Occup Environ Hyg 5(1): 52-9.

Issa Health Service Section (2004). Models and calculation methods to determine exposure to dangerous substances. Conference Review, Dresden: CDROM.
Jayjock MA (1994): Backpressure modelling of indoor air concentrations from volatilising sources. Am Ind Hyg Assoc J 55: 230-5.

Jayjock MA (1997). Modelling inhalation exposure. In: Di Nardi SR. The occupational environment - its evaluation and control. Fairfax, AIHA: 69-74.

Jayjock MA (2005). Exposure modelling research - first things first. The Synergist 16(2): 34.

Keil CB (2000). Mathematical models for estimating occupational exposure to chemicals. Fairfax: AIHA.

Mulhausen JR Damiano J (1998). strategy for assessing and managing occupational exposure. Fairfax: AIHA.

Nicas $M$ (1996). Estimating exposure intensity in an imperfectly mixed room. Am Ind Hyg Assoc J 57: 542-50.

Nicas $M$ (2003). Using mathematical models to estimate exposure to workplace air contaminants. Chem Health Saf (January February): 14-21.

Olcers R (1999). "Use in well ventilated area?". Am Ind Hyg Assoc J 60: 377-83.

Reist PC (1993). Aerosol science and technology. New York: McGraw-Hill.

Roach SA (1981). On the role of turbulent diffusion ventilation, Ann Occup Hyg (24)1: 105-132.

Rong CY, WaiYuan T, Mathew RM, et al. (1990). A deterministic mathematical model for quantitative estimation of historical exposure. Am Ind Hyg Assoc J. 51(4): 194-201.
Schneider T (2002). Improving exposure assessment requires measurements and modelling. Scand J Work Environ Health 28(6): 367-9.

Sottas PE, Bruzzi R, Vernez D, et al. (2005). A Bayesian framework for combining different occupational exposure assessment methods. Proceeding of IOHA Conference.

Kauppinen TP, Pannett B, Marlow DA, Kogevinas $M$ (1994). Retrospective assessment of exposure through modelling in a study on cancer risks among workers exposed to phenoxy herbicide, chlorophenols and dioxins. Scand J Work Environ Health 20: 262-71.

Vernez D, Bruzzi R, Kupferschmidt $H$, et al. (2005). Acute respiratory syndrome after inhalation of waterproofing sprays: a posteriori exposure response assessment in 102 cases, submitted in J Occup Environ Hyg.

Vincent JH (1995). Aerosols Science for Industrial Hygienists. New York: Pergamon Press.

Wadden RA, Scheff PA, Franke JE (1989). Emission Factors for Trichloroethylene Vapor Degreasers, Am Ind Hyg Assoc J, 50(9): 496-500.

Address for correspondence

Raffaella Bruzzi

Institut universitaire romand de Santé au Travail

Rue du Bugnon 19

CH-1005 Lausanne

Tel.: 021/ 3147434

Raffaella.Bruzzi@hospvd.ch 